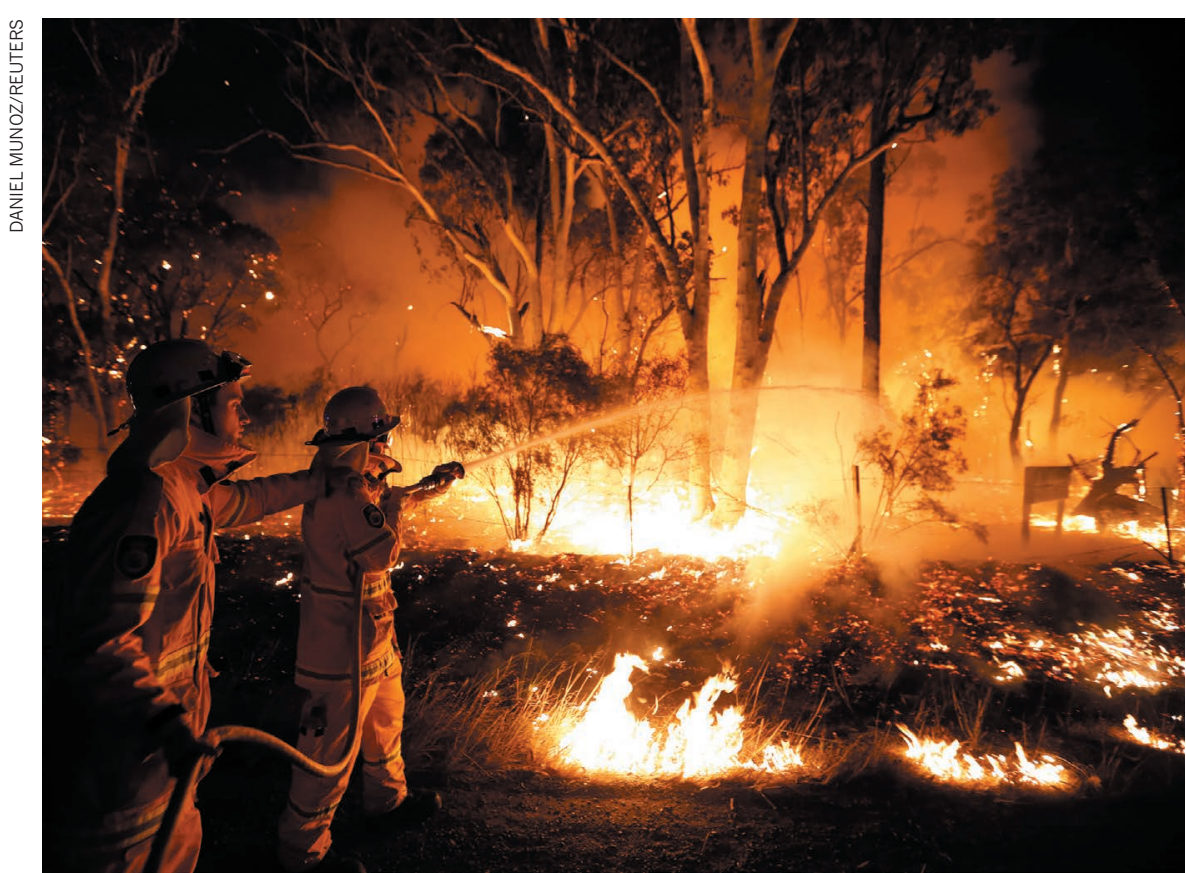

Climate forecasts indicate that Australia will face an increased risk of severe droughts and bush fires.

To be useful, he says, the forecasts would need to be on a time scale that is specific to a business or government's climate vulnerabilities, such as a period of months to years, or on small spatial scales, such as the size of a farmer's field. "That's hugely challenging," he says. "It's the difference between building a car that travels around Sydney and building one that wins a Formula One Grand Prix."

In theory, it should be possible to make such forecasts, but "it's a huge undertaking to actually do it", says Pitman; and it would require high-performance supercomputers generating massive amounts of data.

\section{A QUESTION OF SCALE}

No country can yet produce climate forecasts on the scales and with the accuracy needed for detailed planning, says Simon Mason, a climate scientist at Columbia University's International Research Institute for Climate and Society in Palisades, New York. Even the best forecasts are highly uncertain, which makes it difficult to use them for planning, he says.

For instance, if a farmer's bank wants to know the probability that the farm might experience drought, a 10 -year projection might suggest a $60 \%$ chance of more frequent droughts, says Mason. But that doesn't indicate how severe the droughts might be or whether they will lead to crop failures, he says. "These are exactly the types of questions that need a lot of research."

But Jacqueline Peel, who specializes in climate-change law at the University of Melbourne, Australia, says that companies are likely to face more lawsuits like the Australian one, meaning that they won't have time to wait for fine-scale, tailored models. She says that there is already sufficient information on future warming scenarios for a business to disclose its vulnerabilities.

In Australia, researchers say that budget cuts haven't helped. A report released earlier this month by the Australian Academy of Science identified major gaps in climate research and climate services. The report found that Australia needs an additional 77 climate scientists, including 33 in modelling and 12 in climate services. The academy commissioned the report after the Australian

\section{"These are exactly the types of questions that need a lot of research."} national science agency, the Commonwealth Scientific and Industrial Research Organisation (CSIRO), axed about 30 climate-science positions in 2016. CSIRO says it later added back 31 posts.

"There is a pressing need to improve projections of extreme-weather events to meet the demand for adaptation planning and disaster risk management," the report said.

The situation is better in Germany, the Netherlands and the United Kingdom, which have well-established, government-funded systems that provide climate information. But in the United States, researchers say that climate services are fragmented and struggle to meet the needs of governments or privatesector decision-makers. The Obama administration tried to launch a climate services division, but the US Congress blocked that effort.

"We haven't invested as much in climate services in time scales from several weeks to decades in the US," says John Furlow, who works on climate change and development at Columbia.

\section{SCIENCE DIPLOMACY}

\section{US science envoy resigns}

\author{
Energy researcher faults \\ US president's positions on \\ climate change and racism.
}

\section{BY JEFF TOLLEFSON}

A n energy researcher at the University of California, Berkeley, resigned his post as a science envoy for the US Department of State on 21 August, citing President Donald Trump's "attacks on the core values of the United States".

In a resignation letter addressed to Trump, Daniel Kammen criticized Trump's equivocal response to violent protests by white supremacists in Charlottesville, Virginia, on 12 August. Kammen also condemned the Trump administration's "destructive" policies on energy and the environment, which he said have affected his work as a science envoy. They include Trump's decision to pull the United States out of the 2015 Paris climate pact.

"Your presence in the White House harms the United States domestically and abroad and threatens life on this planet," wrote Kammen, whose term was set to end next month. The first letters of each paragraph in his message spell out the word "impeach".

Former president Barack Obama created the science-envoy programme in 2010 to boost outreach and partnerships with predominantly Muslim countries. The effort, which is run by the state department, has since expanded to cover the globe. Kammen is one of 18 scientists who have participated in the envoy programme; his work in Africa and the Middle East has focused on national security, jobs and sustainable energy.

The White House did not immediately respond to requests for comment. A statedepartment official confirmed that Kammen was one of three active science envoys and said that the department is in the process of appointing more. The department declined to comment on Kammen's resignation letter.

Andrew Rosenberg, who heads the Center for Science and Democracy at the Union of Concerned Scientists in Cambridge Massachusetts, says that Kammen's letter illustrates the moral and ethical quandaries that Trump's policies have created for scientists who serve the US government.

"For the science envoys like Dan, where you are going and representing the United States, it's particularly difficult," Rosenberg says. "It's a personal struggle that everyone has to go through." - 